\title{
Almost Overwhelmed
}

\section{KRIS COHEN}

Associate Professor, Reed College

\section{ABSTRACT}

A review of the 2019 Seattle Art Fair.

It's no secret that the Seattle Art Fair began in a bid, as one commentator put it, to melt "the iceberg of upper-middle-class techies." " So it was a severe blow to the Art Fair, in its fifth iteration, when Paul Allen died. It was Allen's Microsoft fortune that funded the first and all subsequent Art Fairs in Seattle. With his death, the Fair lost its biggest patron, its strongest lure for the art dealers of socalled blue chip galleries - galleries that by and large attended last year's Fair but pulled out of this one - and its best connection to Seattle's ascendant tech community and that iceberg of wealth.

Seattle is famously home to many tech billionaires (Bezos [Amazon], Gates [Microsoft], Allen, Schultz [Starbucks]), but of course to even more tech millionaires. The promise they represent has sustained the Fair's optimism through the lean early years and, perhaps, now, beyond its Paul Allen era-although that remains to be seen. The L.A. art dealer's image of upper-middle-class tech wealth as an iceberg is...suggestive. He probably only meant to communicate an idea of vastness that is, for now, hidden and untapped: if vast wealth like Paul Allen's formed the tip of the iceberg, then the upper middle class lies just under the surface, an even larger base of support to be mined. But in the immediate aftermath of Iceland holding its first funeral for the death of an iceberg, the 700-year-old Okjökull, this association of Seattle techies with melting icebergs, long-ignored harbingers of environmental disaster for the world's most vulnerable populations, pushes us to think not about scale so much as about the sort of person we are referring to when we're talking about tech's middling elite. ${ }^{2}$ Perhaps this helps to explain why post-humanism of some sort was on artistic director Nato Thompson's mind as he curated the Fair for the second year. ${ }^{3}$

Before they knew of Allen's death, the organizers of the Fair (Vulcan Arts and Entertainment, headquarters for all of Allen's philanthropic projects) asked Nato Thompson to be the artistic director. Thompson is an art critic, writer, and curator, known as a public intellectual and champion of new art and especially of new genres. He is currently artistic director at Philadelphia Contemporary and was formerly curator of Creative Time in New York. His visible work for the Fair consisted in inventing a theme-for this year that theme was the Wunderkammer, the curiosity 
cabinets of the $16^{\text {th }}$ and $17^{\text {th }}$ centuries ${ }^{4}$ - and curating a set of projects whose relationship to the Fair itself is, at best, an open question. But the very fact of his curatorial work, regardless of its content, can't help but offer a sheen of intellectualism and autonomy to an art fair whose principle of selection is and must be about very little more than what sells. Is that what middle-class techies want, some critical distance from the commodity market they serve and improve? Maybe. What is certain is that those side projects are bait for people like me, people who write about art. They seem to offer something more historically suggestive, more richly symptomatic than the blunt category that which sells - although it will be no surprise to anyone, least of all Thompson or Allen, that such a critical edge is a selling point precisely for its sheen of the non-commercial.

These curated events included a conversation between Richard Pell of the Center for Postnatural History and artist Stephanie Dinkins on artificial intelligence/artificial life, and installations by Dinkins, Pell, Bigert \& Bergström, Gregory Blackstock, Hironaka \& Suib, and Pearl Jam guitarist Mike McCready collaborating with Kate Neckel. As for the Fair itself - the part organized by galleries and not by Thompson-it's hard to know what to say by way of introduction or generalization. I myself saw no obvious patterns (as in, what's hot this year), and I worry that the only available genre for generalization about art fair art, at least in the idiom of critical discourse, is snark. Then again, even if I had discerned something that could help you gain a sense of just what was shown there, and if I could then articulate those ideas here, would I be conveying information about the Fair? About the speculative marketplace for art? About the artists themselves? The speculative marketplace plus the aesthetic tastes of the assembled gallerists? Paul Allen? Seattle? My worry, aside perhaps from my inability to sense such meaningful patterns, is that any such attempt would sound far too meaningful. It will, for example, mean something to some readers that, after Paul Allen's death, many "blue chip" galleries (those are sneer quotes), such as David Zwirner in New York City, pulled out of this year's Fair-some will feel that the remaining art is second-tier or less serious. One critic draws the opposite conclusion, mobilizing the withdrawal of blue chip galleries as evidence toward an argument that something more than just the crassly commercial is going on. Referring to Thompson's decision to include a number of what the author calls "interactive displays," by which they mean the curated work of Dinkins, Pell, Bread Face (on whom, more below), and others, the critic concludes: "In this new, post-Paul Allen Seattle Art Fair, his [Thompson's] decision — whether by design or accident — could be registered as a reminder that art can function beyond its monetary dimensions, and engage the audience with important issues."

Perhaps. Here is Thompson working hard to articulate important issues: "Fast forward to this intersectional $21^{\text {st }}$ century where the mutability and interwoven qualities of all forms of life and non-life are distinctively embedded in literary, political, artistic, and scientific discussion." "Intersectional" here gestures first toward the "interwoven qualities of all forms of life." But it carries a fortuitous and unspoken secondary connection to black feminism, where there has been a sustained conversation about intersectional politics. ${ }^{6}$ Stephanie Dinkins, the Fair's only evidence of any sort of actual commitment to black feminism, showed an iteration of her ongoing work on artificial intelligence and black memory. Entitled "Not the Only One (N'TOO)" (Figure 1), 
Dinkins's project is, as the Fair's press describes it: "a multigenerational memoir of one black American family told from the 'mind' of an artificial intelligence with evolving intellect." Built around a growing oral history archive from Dinkins's own family, her AI device, situated on a plinth in a small room, fielded questions from the Fair's mostly white patrons. If the answers were unsatisfying - and there were murmurs to that effect - the ambiguity of this dissatisfaction seemed to be less an oversight and more what the work was about: is the very idea of AI to blame? The nascency of Dinkins's archive? The constitutive failure of all archives in the context of black life? The presumption that an intersubjective circuit in this context is either possible or desirable?

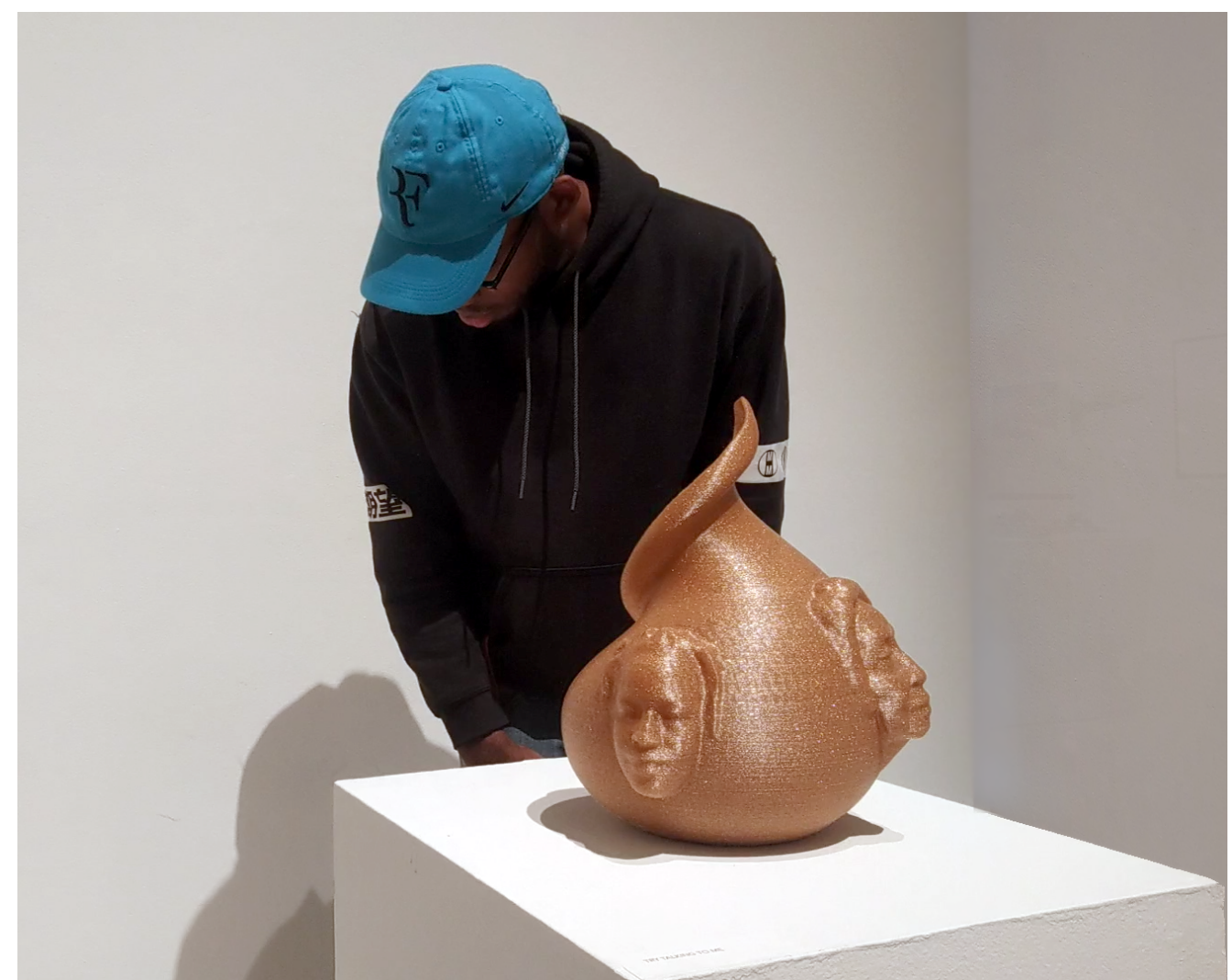

Figure 1. Stephanie Dinkins, Not the Only One (N'TOO), 2017, 3D printed sculpture, custom software, custom plinth, $15 \times 10 \times 10$ in. $(38.1 \times 25.4 \times 25.4 \mathrm{~cm})$. Seattle Art Fair, Seattle, WA. Installation photo courtesy Seattle Art Fair.

But if one were nominating candidates for the post-human class best accommodated by the Seattle Art Fair, one would have to name not Dinkins's black AI, but Bread Face (Figure 2). Bread Face is an Instagram star and performance artist who was included under the umbrella of Thompson's "Wunderkammer" theme. The most neutral description of her practice reads as sensationalist and sells articles in major newspapers: an Asian woman, on the internet, famous for ritually and stylishly pushing her face into bread. ${ }^{8}$ No particular type of bread. Commentary about her practice 
evinces the internet's persistent love affairs with sex, sex-phobia, and orientalism. But if the commentary isn't outright fandom, then the subtext, faintly or overly condescending, is always about how the internet has the capacity to monetize the absolutely un-monetizable: the fact that the internet can seemingly make anything popular, and anyone rich, given the right conditions. It's the American Dream re-imagined for the era when it has become impossible to continue believing in the promise of the American Dream. This evokes quite a different idea of the post-human: not abject but exoticized, not immiserated but alluring and enterprising, not running in flight from rising, warming dead seas, but radiating a warm, mildly erotic calm.

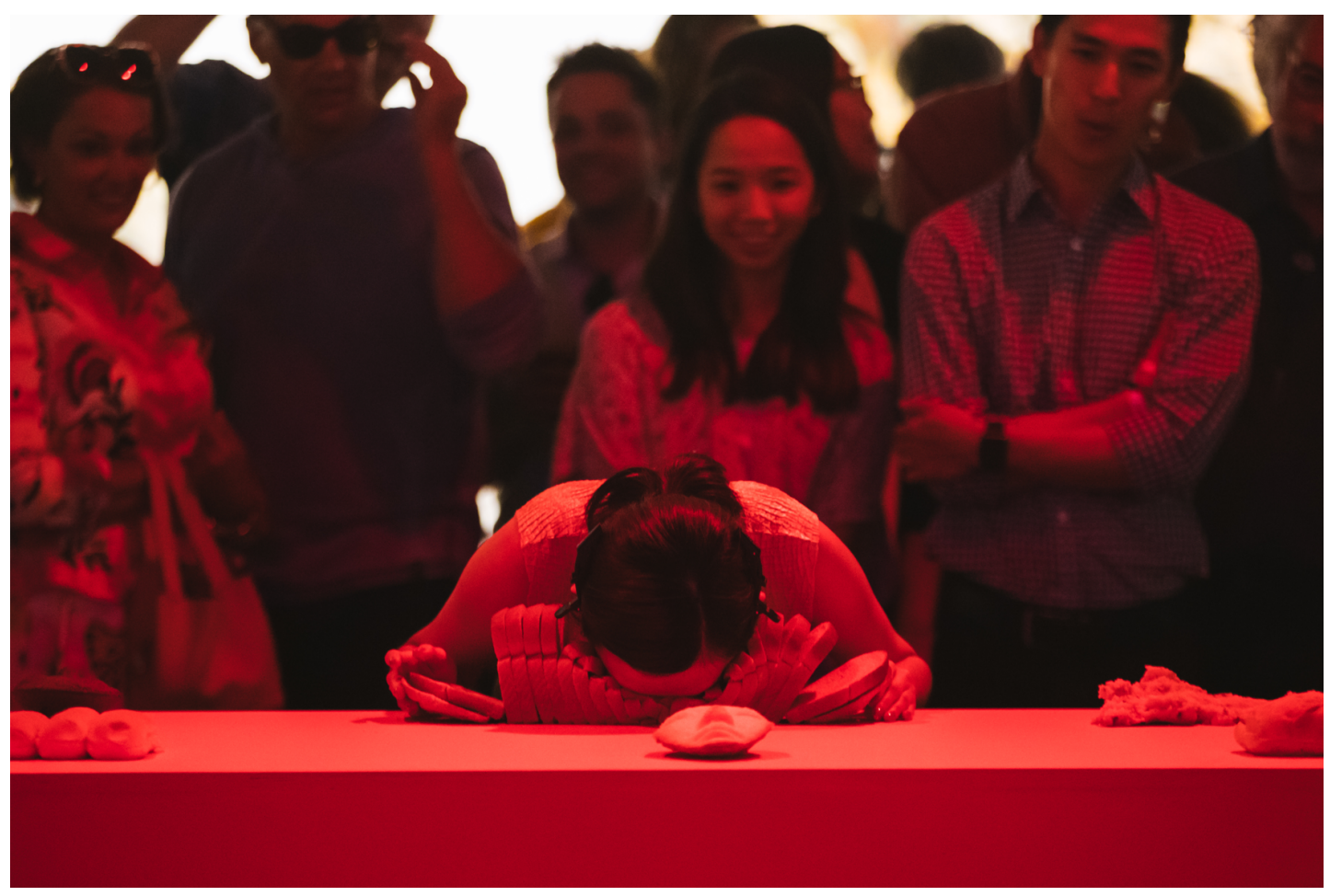

\section{Figure 2. Bread Face, Self Facing, 2019, interactive installation. Seattle Art Fair, Seattle, WA. Photo courtesy Seattle Art Fair.}

In fact, as the Seattle Art Fair press materials noted, Bread Face has become a star in the ASMR scene. ASMR stands for Autonomous Sensory Meridian Response, the pseudo-scientific name given to a physical sensation, often described as a tingling that induces relaxation, calm, even a sense of well-being. ASMR is now also the name for a large and fervently self-regarding internet community that insists again and again that theirs isn't a sexual subculture even while their videos play openly with old sexualizing tropes such as the exoticized Asian woman. ${ }^{9}$ But it's a large movement with a variety of opinions and eroto-phobia is hardly confined to that corner of the world. 
For her part, Bread Face (she prefers to stay anonymous) describes herself as an artist, but her presence at the Fair was clearly trading on her social media stardom. In a large and central performance space at the Fair, people amassed to witness Bread Face performing live and to step into a booth that allowed them to push their own faces into bread. But as advertisers have started to discover, the calming, mildly erotic, soporific qualities of ASMR also, whatever their other benefits, put one in a buying mood. The relaxed state of the ASMR subject is now thought to be related to the ideal receptive state of the advertising subject. Of course, much of the advertising industry's evidence for such a claim comes from deploying ads rather than researching the viability of deploying such ads (but that is, in the main, what counts as research in internet-adjacent economies). ${ }^{10}$ Bread Face has been commissioned by a jewelry company, an idea that the company might well have gotten from Bread Face herself, who has used her Instagram account to advertise her own products. ${ }^{11}$ What's of interest for my purposes isn't the scandal of something else being commodified (What? Even ASMR?!) — there are just as few boundaries around what counts as an ad as there are around what counts as art; this truism is as old as modernism itself and possibly synonymous with it. What is of interest is what happens at the confluence of the two features of the Seattle Art Fair that I've singled out: a kind of live ASMR event and the Fair's ongoing — and this year, in the wake of Allen's death, even more desperate-desire to attract only moderately gaudy middle-tier tech money, which is to say, to get privileged but not super-elite tech industry workers to be attracted enough to art to buy some, to see it as a hobby, a way of life-or however it is that such buyers might measure their proximity to the good life.

Here, at the nexus of contemporary art and ASMR, something Paul Allen once said about the experience of art is relevant. Art, he said, can be "almost overwhelming." 12 The sentiment draws out a connection between art and ASMR because it can also stand as a description of the affective state of ASMR. ASMR is a pseudo-science of soothing. When it works, it induces an aesthetic or sensory response of being almost overwhelmed. The ASMR state, the normative one anyway (as it's reported - and it is prolifically reported), is about a kind of titillation that expends itself not in an outpouring of desire or lust or frenetic bodily energy, but a kind of quietly internal peace state. It's a deeply private state, even when one is in public, as was the audience for Bread Face at the Fair. It is "autonomous" because it is automatic, not controllable by will or effort, but also because, as such, it is self-governing (provided we don't conflate self with conscious self). It is something that happens to people, as though spontaneously. The fact that one can find content that triggers one's own idiosyncratic response-people in the scene frequently comment on the particularities of their "triggers" - is due not to the predictability or conventionality of the sensation, but to the way the internet capacitates such a vast marketplace for ASMR triggers. And like many internetbased marketplaces, its overt target is not actually a market or a demographic - no such agglomeration of people-but the autonomous individual. The fact that other people might occasionally feel what you feel only confirms, even amplifies the sense that one's ASMR triggers are uniquely one's own, somehow so idiosyncratic that even the possessor of that sensation can't really explain why it works - but are certain that it does (ASMR is a Kantian aesthetic, to this extent). The action of ASMR is toward this enclosed self. The enclosed self is in fact not only 
ASMR's desired end state, but also the predicate that makes that very end state possible. ASMR might be a form of pleasure for some precisely for the way it creates but also reinforces that enclosure, as though activating a dormant or underutilized capacity. People often say they "discover" their capacity for ASMR; the feeling for most seems to be that it was there all along, simply awaiting the appropriate stimulus.

This is why binaural microphones, which simulate such enclosure in an audio recording, are state of the art for ASMR creators. Binaural recordings simulate a head's own auditory apparatus, and produce recordings that are meant to be experienced as though the recorded sound were emanating from inside the head of the listener, or as though the ASMR artist were speaking to you and only you, from inside your very ear (immanating would be more appropriate, were it a word). There's always a lot of whispering and close talking in ASMR recordings, along with extra-diegetic encouragement to listen through headphones. As one would expect from this description, the standards of judgment for what constitutes good or effective ASMR are absolutely relative across the ASMR community. But they are absolute within the individual. ASMR is both absolutely subjective, and absolutely empiricist (precisely on the basis of its subjectivity) — as so many of its adherents affirm, it either happens to you or it doesn't. One doesn't find many descriptions of middle states, of the sensation half-happening or almost happening.

All of this makes ASMR the dream of the tech world, which has for so long entrusted its politics to precisely this model of the autonomous individual, the individual made autonomous by the technologies he [sic] would invent-first as a hippie, later as an entrepreneur. The individual set free within a system whose ethics were to have been guaranteed by its technological rationality, which was itself measured through the same on/off mechanism that ASMR enshrines within the autonomous individual: it works or it doesn't; it sells or it doesn't. Absolutely rationalized, absolutely individual - this is the tech industry's motto and its alibi. As so many women and people of color in the tech industries attest, hirings and firings are often justified by this very logic: the new employee is either a good "cultural fit," or they are not. They just didn't make us tingle, managers and co-workers say. This is how the tech world flatters itself for its good instincts while antagonizing those who challenge its cultures and the assumptions of those cultures. Herein lies the notion, so often voiced in the tech world, that since the sixties the American tech industry has perfected the Liberal post-racial state wherein a spirit of diversity reigns not because there is anything like equality but because no one cares what you look like. By fusing the subjective and the empiricist within the enclosed self-the self as enclosure-ASMR embodies the values that allow this post-racial ethos to co-exist peaceably with the ongoing exclusion and ostracization of historically marginalized and vulnerable people of all sorts. This, in short, is the mode of racial whiteness that has evolved in today's tech industries - and it is precisely this magnanimous, inclusive whiteness that the Seattle Art Fair courts with its inclusion of Dinkins's black AI under the universalizing banner of the post-human, and in its inclusion of Bread Face's ASMR aesthetic. 
When I talk about whiteness, I am talking not about a demographic category so much as a set of attitudes that congeal in certain beliefs about autonomy, about freedom, about meritocracy and the standards one has to actively obscure to keep the ideal of a meritocracy alive. Any type of body can enact those attitudes, although these attitudes have been so pervasive and unquestioned in big tech that they are often entirely depersonalized - less a bad attitude than a kind of bad atmosphere. Robin James notes that what she calls "multi-racial white supremacist patriarchy" doesn't define race as a phenotype, or even bodily at all, but as "the right kind of response or outcome of one's response to underlying conditions"-conditions such as racism itself. The right kind of raced person, by this logic, would overcome whatever conditions and beliefs attach to their race, thereby embracing the post-racial logic that they would thereby be made to perpetuate. Jodi Melamed calls the period defined by this attitude the era of "official antiracism," by which she refers to the coexistence of a stated desire for diversity and a set of policies, norms, and beliefs - including the belief in diversity itself - that actively propagate the exclusive standards that have long made white people white. ${ }^{13}$ James, Saidiya Hartman, and others understand this peculiar form of power as propagated by an ethos that values, above all, free choice pursued inside the iron structure of personal responsibility. ${ }^{14}$ In this logic, racializing effects become the responsibility of the raced and not of the white power structures that enact that racialization, which can now perpetuate themselves not (only) through violence but through meritocratic color-blindness. ${ }^{15}$ But this form of power, which has so defined tech cultures since the sixties, is about more (or less) than just choice as a form of self-determination. It is also, like ASMR, about having the right kinds of instincts, the right kind of bodily responses or gut feelings — utterly subjective, utterly unquestionable. The right kind of match, in other words, between one's instincts and one's environment, registered as something automatic, magical, a kind of tingling. If a job candidate doesn't share a company's commitment to color-blind hiring practices, their loss. No one to blame really-except the raced person themselves, who might, if they complain, be accused of playing the race card and are often, in this context, themselves called racist. Or as a tech scion recently tweeted in an unwitting paean to his own whiteness: "We are all people of color."16

ASMR captures the tech industry's ardent desire not to have to think at all about that which it doesn't deem profitable or interesting, to carve out realms of management and government that can be ruled by a higher form of gut feeling. ASMR is thus the perfect lure for a tech industry understood as a potential market, where the values advertised (here by the Seattle Art Fair) are less about the actual people who work in the tech industry and more about an imagination of what the tech industry seems to embody, how its richest and most powerful members like to see themselves. ASMR affect focuses the world down to a single, tunneled experience, where other selves, reduced to voices that emanate as though from inside the head of the perceiving subject, are rendered as nothing more and nothing less than an opportunity to feel one's own feelings (an innovation on the thought, familiar since Thatcher articulated it and Reagan enacted it, that sociality in a neoliberal context gets cemented through competition — or replaced by it $^{17}$ ). As Black feminists have been saying for so long, this autonomous response, as we can now name it, is a long-standing Liberal fantasy never really afforded to marked bodies, except as the burden that allowed subservience, 
marginalization, and slow death to proceed by means other than physical domination. ${ }^{18}$ That kind of autonomy set in place a system of laws and extra-legal strictures that made everything that happens in and to one's life the sole responsibility of the individual—a real boon for whiteness and for most white people, who could thereafter be seen as deserving of their generational wealth and privilege. When autonomy grants responsibility, anything structural gets erased in the bargain. ${ }^{19}$ Who, then, would need or find powerfully restorative an autonomous sensory meridian response? Anyone who feels that that autonomous feeling is theirs or was once theirs and worries that it might now, under pressure from various scandals of toxic masculinity and exposures of racist and misogynist hiring practices, be under threat or in short supply, a once universal but now finite commodity. The sound of whiteness, as comedian Randall Otis performs it in his video "ASMR for White Liberals," would be a binaural microphone recording of a soft black voice saying whatever the listener needs to hear to feel the warm tingles of self-enclosure inside their own inclusive whiteness. ${ }^{20}$ But for anyone whose life has been defined more through various forms of forced, remaindered collectivism and the survival skills that have made those spaces livable and sometimes bearable, this fantasy, and so the reparative power of ASMR, might be empty, a null set.

But still, one might wonder if the Seattle Art Fair challenges this aspect of the tech industry, or reproduces it as a structure of identification for the people whose wealth they would like to tap. I've said nothing that would definitively tip the case either way, and the presence of an ASMR artist in this year's Fair doesn't dictate an answer. In either case, the presence of Stephanie Dinkins's project, which breaks any universalizing, post-racial pretentions sheltered in AI's notions of intelligence by seeding it with a database of black memory, makes trouble for any generalizing assessment of the Fair's intentions. But whiteness was never just about intention. ASMR gets that part of whiteness right, too. The pleasures it offers are precisely about short-circuiting selfconscious intention as a basis for decision, action, effect. My own desire has been less to blame the Seattle Art Fair for anything than to use the Fair's staging of an encounter between ASMR and middling tech wealth as an excuse to think about what it means to court the millionaires of the tech industry - to think more about what one is actually courting in the constitution of that tier of the industry as a market. Maybe the most we can say about the Seattle Art Fair's role in all this comes in the form of a question: if they succeed in attracting the millionaires of the tech industry, what will they do with them, which is to say, what will they do with the logics in and through which they've achieved their success and which have provided the financial means for affording art in the first place? And more vexing still: can the desire to make the Seattle Art Fair into an inviting space for this large middle tier of the tech industry do anything but propagate, in the art the Fair wants to hang over their couches, the racial logics that the tech industry in Seattle and beyond have made so pervasive and so synonymous with the very idea of American success? If I say these are not rhetorical questions, I mean that the answers aren't predetermined, even if those on the outside of these logics will nod with weary, seething recognition about how this is all likely to turn out. 


\section{ENDNOTES}

1. Quoted in Jen Graves, "The Seattle Art Fair Was So Successful, the City Literally Applauded," The Stranger. Accessed August 7, 2019.

https://www.thestranger.com/features/feature/2015/08/05/22647397/the-seattle-art-fair-was-sosuccessful-the-city-literally-applauded.

2. Agence France-Presse, "Iceland Holds Funeral for First Glacier Lost to Climate Change," The Guardian, August 19, 2019, https://www.theguardian.com/world/2019/aug/19/iceland-holdsfuneral-for-first-glacier-lost-to-climate-change.

3. "Q\&A: Nato Thompson Shakes Things Up in His Second Year as Seattle Art Fair's Artistic Director," Observer (blog), July 30, 2019, https://observer.com/2019/07/nato-thompson-seattleart-fair-interview-what-to-see-programs-art-talks/.

4. Barbara Maria Stafford, Devices of Wonder: From the World in a Box to Images on a Screen (Los Angeles, CA: Getty Research Institute, 2001).

5. "How the Seattle Art Fair Is Recalibrating After the Death of Founder Paul Allen and HighProfile Gallery Defections," artnet News, August 5, 2019, https://news.artnet.com/market/seattleart-fair-2019-1617184.

6. Kimberlé Crenshaw, "Mapping the Margins: Intersectionality, Identity Politics, and Violence against Women of Color," Stanford Law Review 43, no. 6 (1991): 1241-99.

7. Saidiya V. Hartman, Wayward Lives, Beautiful Experiments: Intimate Histories of Social Upheaval (New York, NY: W.W. Norton and Company, 2019); Stephen Best, None Like Us: Blackness, Belonging, Aesthetic Life, Theory Q (Durham and London: Duke University Press, 2018).

8. Katie Rogers, "This Is Her Face. This Is Her Face in Bread. Any Questions?," The New York Times, January 7, 2016, sec. Style, https://www.nytimes.com/2016/01/08/style/this-is-her-facethis-is-her-face-in-bread-any-questions.html; Nikki Gillil, "What Is ASMR and Why Are Brands like KFC Getting Involved?," Econsultancy (blog), September 19, 2016, https://econsultancy.com/what-is-asmr-and-why-are-brands-like-kfc-getting-involved/.

9. Edward W. Said, Orientalism, 1st Vintage books ed. (New York: Vintage Books, 1979).

10. Gillil, "What Is ASMR and Why Are Brands like KFC Getting Involved?"

11. Angela Natividad, "Bread Face Made an Ad for Jewelry While Mashing Her Face Into Baked Goods," Adweek, October 30, 2017, https://www.adweek.com/creativity/bread-face-made-an-adfor-jewelry-while-mashing-her-face-into-baked-goods/.

12. The full quote was this: "It's really amazing to stand in front of a work you haven't seen before and be almost overwhelmed by its beauty and the vision and execution of the artist." Paul G. Allen, comments made at the 2016 Seattle Art Fair, https://www.paulallen.com/arts-andculture/the-why-behind-the-seattle-art-fair [last accessed 02.20.20]

13. Jodi Melamed, Represent and Destroy: Rationalizing Violence in the New Racial Capitalism (Minneapolis: University of Minnesota Press, 2011). 
14. Hartman calls this "burdened individuality." Saidiya V. Hartman, Scenes of Subjection: Terror, Slavery, and Self-Making in Nineteenth-Century America, Race and American Culture (New York: Oxford University Press, 1997).

15. Robin James, "Notes On A Theory Of Multi-Racial White Supremacist Patriarchy, Aka MRWaSP," accessed September 13, 2019, https:/www.its-her-factory.com/2013/11/notes-on-atheory-of-multi-racial-white-supremacist-patriarchy-aka-mrwasp/.

16. https://witter.com/RichMartel/status/1168883724756422658?s=20 [last accessed 09.09.19]

17. Wendy Brown, Undoing the Demos: Neoliberalism's Stealth Revolution (Cambridge, MA.:

MIT Press, 2015); David Harvey, A Brief History of Neoliberalism (New York: Oxford University Press, 2005).

18. Saidiya V. Hartman, Scenes of Subjection; Katherine McKittrick, "Mathematics Black Life," The Black Scholar 44, no. 2 (2014): 16-28, https://doi.org/10.5816/blackscholar.44.2.0016; Alexander G. Weheliye, "Introduction: Black Studies and Black Life," The Black Scholar 44, no. 2 (2014): 5-10; Hortense J. Spillers, "Mama’s Baby, Papa's Maybe: An American Grammar Book," Diacritics 17, No. 2 (1987): 65-81. The thought about the "burden" of freedom and autonomy is from Saidiya V. Hartman, Scenes of Subjection.

19. See also Wendy Chun, Control and Freedom: Power and Paranoia in the Age of Fiber Optics (Cambridge: MIT Press, 2006).

20. Randall Otis, "Randall Otis on Twitter: 'ASMR for White Liberals,", Twitter, accessed September 17, 2019, https://twitter.com/randallotistv/status/1110947319938248704.

\section{AUTHOR BIO}

Kris Cohen is associate professor of art and humanities at Reed College. He works on the relationship among art, economy, and media technologies, focusing especially on the aesthetics of collective life. His first book, Never Alone, Except for Now (Duke University Press, 2017), addresses these concerns in the context of electronic networks. He is working on a new manuscript that accounts for how a group of Black artists working from the sixties to the present were addressing, in ways both belied and surprisingly revealed by the language of abstraction and conceptualism, nascent configurations of the computer screen and the forms of labor and personhood associated with those configurations. 